\title{
Pattern of accident distribution in the telecommunications industry
}

\author{
P R DAVIS AND N J SHEPPARD \\ From the Materials Handling Research Unit, Department of Human Biology and Health, University of \\ Surrey, Guildford, Surrey
}

\begin{abstract}
Examination of the accident records from the telecommunication industry covering some 100000 engineers over a 12-month period showed that $25 \%$ of accidents resulting in more than three days' sick leave gave rise to back injuries. Handling accidents and falls accounted for $65 \%$ of threeday-plus accidents; handling accidents alone gave rise to $65 \%$ of back injuries. The absolute numbers of accidents have been compared with the total population of engineers to estimate the effects of age or occupation on levels of hazard; certain occupations constituting $33 \%$ of the engineers' population suffered $70 \%$ of all three-day-plus accidents. Accidents occurred most frequently in the group aged from 31 to 48 years. Other significant factors affecting the occurrence of accidents were time of year and duty experience of the workers.
\end{abstract}

The telecommunications industry (TI) has a population of some 100000 male engineers and an accurate computerised accident reporting procedure. The data available include the occupation, age, and experience of employees at the time of report; the date; the stated cause and bodily site; and the duration of incapacity. Types of work encountered in different occupations vary widely, from heavy manual work to delicate work needing much manual dexterity. Thus it has proved possible to relate injury rates with occupation, and to look at other factors causing accidents in a large population.

The purpose of this study was to determine which occupations within the industry suffer the highest accident rates, which type of accident is most frequent in high hazard occupations, and the ages and experience of those suffering the accidents. This knowledge could then permit a detailed investigation of cause and thus indicate preventative measures.

\section{Method}

The accident records, collected at monthly intervals over the 12-month period from May 1977 to April 1978 in punch-card form, were analysed using the statistics package for the social sciences. ${ }^{1}$ The records were coded so that they could be analysed

Received 31 January 1979

Accepted 5 July 1979 subsequently for sex, age, occupation, duty experience, date of accident, time, sick leave required, cause of injury, nature of injury, and part of body affected. To relate some of the distributions obtained to the total working population an age breakdown of all the engineers as at 31 March 1977 was obtained, also a breakdown by occupation. An age distribution in selected occupations was obtained from a sample of some 900 employees ( $1 \%$ of the total workforce). While records were available of all accidents, detailed analysis was restricted to those resulting in absence from work of three days or more. The accident rate per thousand employees at risk was calculated for comparative purposes between the various categories studied.

\section{Results}

Over the 12-month period a total of 13058 accident records were received; 9477 of these patients needed no sick leave, 1214 resulted in one to three days' off, and the remaining 2367 required more than three days' sick leave, giving an overall mean accident rate of $120 \cdot 3$, and a mean accident rate for three-day-plus accidents of 22.4 per 1000 men at risk.

The incidence of all accidents varied significantly throughout the year (fig 1) $\left(\chi^{2}: \mathrm{p}<0.001\right)$; most accidents occurred between September and February.

Table 1 summarises the data concerning bodily site of injuries. Posterior trunk injury is the most common $(25 \%)$, followed by injuries to the ankle 


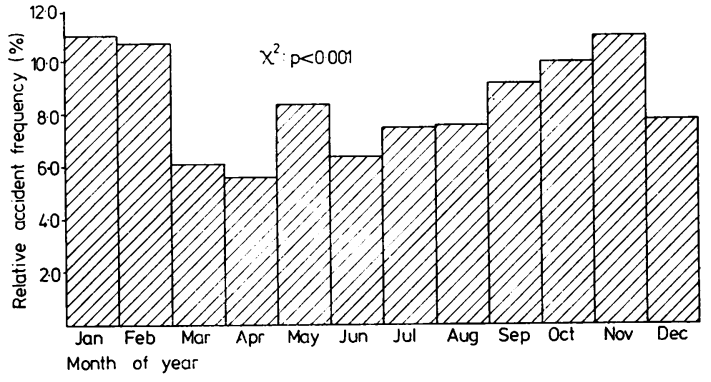

Fig 1 Distribution of three-day-plus accidents by time of year.

Table 1 Distribution of accidents by bodily site

\begin{tabular}{lcc}
\hline Bodily site & No of accidents & Relative frequency $\%$ \\
\hline Posterior trunk & 591 & $25 \cdot 0$ \\
Ankle and foot & 448 & $18 \cdot 9$ \\
Wrist and hand & 395 & $16 \cdot 7$ \\
Leg & 259 & $10 \cdot 9$ \\
Trunk others & 207 & $8 \cdot 7$ \\
Multiple & 174 & $7 \cdot 4$ \\
Arm & 150 & $6 \cdot 3$ \\
Head or neck & 82 & $3 \cdot 5$ \\
Eye and socket & 51 & $2 \cdot 2$ \\
Spinal column & 5 & $0 \cdot 2$ \\
Missing values & 5 & $0 \cdot 2$ \\
Total & 2367 & $100 \cdot 0$ \\
\hline
\end{tabular}

and foot $(18.9 \%)$, and the wrist and hand (16.7\%).

Table 2 shows the differing frequencies of the various accident causes. Handling of materials and falls are the major causes of accident, giving rise to $32.6 \%$ and $32.3 \%$ of the three-day-plus accidents respectively.

Table 2 Distribution of accidents by cause

\begin{tabular}{lcc}
\hline Cause & No of accidents & Relative frequency \% \\
\hline Handling objects & 772 & $32 \cdot 6$ \\
Falls & 764 & $32 \cdot 3$ \\
Sudden movements & 218 & $9 \cdot 2$ \\
Stepping on objects & 187 & $7 \cdot 9$ \\
Hand tools & 175 & $7 \cdot 4$ \\
Objects falling & 111 & $4 \cdot 7$ \\
Others & 134 & $5 \cdot 7$ \\
Missing data & 6 & $0 \cdot 2$ \\
Total & 2367 & $100 \cdot 0$ \\
\hline
\end{tabular}

Of handling accidents, $49.5 \%$ gave rise to back injuries, and, in total, handling accidents account for $64.3 \%$ of posterior trunk injuries; falls account for a further $13.0 \%$ of back injuries.

Investigation of the experience of the employees in the particular jobs in which they were engaged at the time of accident shows that $93.2 \%$ had completed more than 12 months in that particular duty.

The distribution of the accident rate per thousand men at risk for three-year age groups is shown in fig 2 . Those aged under 30 or over 48 have a lower accident frequency than those between 31 and 47 .

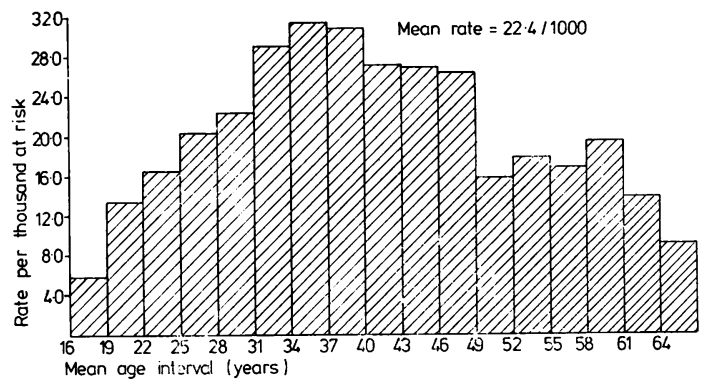

Fig 2 Distribution of three-day-plus accidents by age.

Figure 3 shows the accident rate by duty code. The six highest accident rates were for the following occupations: rodding and cabling, general purpose installation parties, electric light and power installation, maintenance of switching equipment, aerial rigging parties, and cable fault location. Twentythree duty codes had accident rates significantly higher than the overall accident rate $(p<0.05)$ and are referred to as the "top 23" in this paper (table 3). These duty codes encompassed all manual work performed outdoors, where work conditions are less controlled.

The accident rates of all accidents, handling accidents, posterior trunk injuries, and posterior trunk injuries due to handling for the top 23 codes were compared with the other 56 duty codes and the whole population of telecommunications engineers (table 4). From this analysis it appears that the top 23 , which constitute only $33 \%$ of the engineers' population, suffer $70 \%$ of all three-day-plus accidents.

The age distribution of the top 23 obtained from the sample of 900 men differs from that in the full

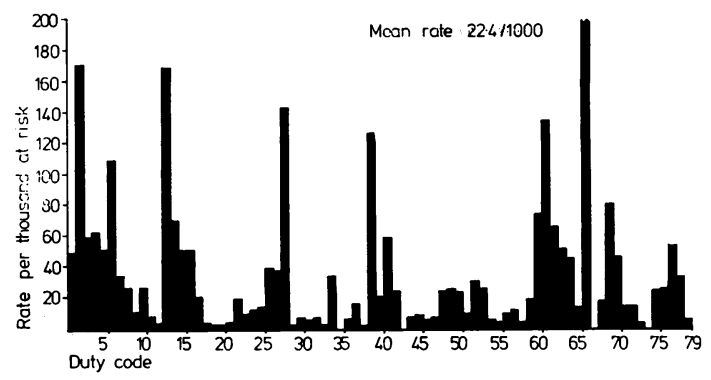

Fig 3 Distribution of three-day-plus accidents by occupation. 
Table 3 Accident rates occurring in top 23 duty codes

\begin{tabular}{|c|c|c|}
\hline Duty code & Job description & Accident rate per 1000 at risk \\
\hline 1 & Cabling in ducts & $49 \cdot 4$ \\
\hline 2 & Rodding and cabling: 3 man parties & $171 \cdot 4$ \\
\hline 3 & General purpose parties: external works & $59 \cdot 1$ \\
\hline 4 & Rodding and cabling: 2 man parties & $61 \cdot 3$ \\
\hline 6 & Pole erection & $109 \cdot 1$ \\
\hline 7 & Works jointers & $33 \cdot 2$ \\
\hline 13 & General purpose parties: installation & $169 \cdot 8$ \\
\hline 14 & Installation jointers & $70 \cdot 9$ \\
\hline 15 & One man installers & $50 \cdot 3$ \\
\hline 16 & Two man installers & $50 \cdot 3$ \\
\hline 27 & Installation electric light and power, lifts, hot water, and ventilation & $36 \cdot 7$ \\
\hline 28 & Control EL \& P works & $143 \cdot 0$ \\
\hline 39 & Maintenance manual exchange equipment & $127 \cdot 1$ \\
\hline 41 & Maintenance transmission equipment including radio equipment & $59 \cdot 5$ \\
\hline 52 & Subscribers' apparatus and line maintenance & $30 \cdot 2$ \\
\hline 60 & External general purpose maintenance & $73 \cdot 8$ \\
\hline 61 & Aerial rigging gangs maintenance & $134 \cdot 0$ \\
\hline 63 & Pole testing & $50 \cdot 0$ \\
\hline 64 & Maintenance jointers and faultsmen & $46 \cdot 5$ \\
\hline 66 & Cable fault location & $205 \cdot 0$ \\
\hline 69 & Box building & $81 \cdot 3$ \\
\hline 77 & Transport control and drivers & $54 \cdot 0$ \\
\hline
\end{tabular}

Table 4 Summary of three-day-plus accidents in the telecommunications industry

\begin{tabular}{|c|c|c|c|}
\hline & $\begin{array}{l}\text { All duty } \\
\text { codes }\end{array}$ & $\begin{array}{l}\text { Top } 23 \\
\text { codes }\end{array}$ & $\begin{array}{l}\text { Other } 56 \\
\text { codes }\end{array}$ \\
\hline Overall accident rate ${ }^{*} \dagger$ & $22 \cdot 4$ & 46.9 & $10 \cdot 4$ \\
\hline Back injury rate + & $5 \cdot 6$ & $12 \cdot 3$ & $2 \cdot 3$ \\
\hline Handling accident rate* $\dagger$ & $7 \cdot 3$ & 16.0 & $3 \cdot 0$ \\
\hline $\begin{array}{l}\text { Back injuries due to } \\
\text { handling rate*+ }\end{array}$ & $3 \cdot 6$ & $7 \cdot 8$ & $1 \cdot 5$ \\
\hline Total No of accidents $\uparrow$ & 2263 & 1563 & 700 \\
\hline No of employees & 100931 & 33335 & 67596 \\
\hline
\end{tabular}

*Rate per 1000 at risk.

†Omitting accidents occurring during activities not covered by engineering duty codes.

population in having a lower proportion of employees in the younger age groups $(22 \cdot 1 \%)$ and a higher proportion in the middle age groups $(52.8 \%)$ compared with $34.3 \%$ in the younger age groups, and $31.6 \%$ in the middle age groups in the total population. The observed number of top 23 accidents, however, is twice the number expected (derived from the predicted age distribution of the top 23 if one applies the sample population, and the overall accident rate for each age group). The distribution of back injury rates in the top 23 then shows an increased rate in the younger workers-the 22-33 year olds, as compared with that for the whole population (fig 4).

The top 23 have a greater proportion of accidents caused by handling objects than the rest of the engineering occupations, and they more frequently meet handling problems with poles, ladders, jointboxes, and manhole covers.

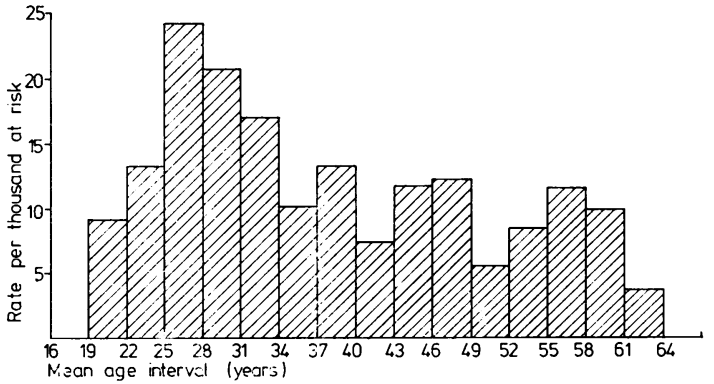

Fig 4 Distribution of back injuries by age in occupations with highest injury rates.

\section{Discussion}

An important observation of this analysis has been the high incidence of accidents, back injuries, and handling accidents occurring to telecommunications engineers in certain occupations. The overall annual incidence of 22.4 equates well with a rate of 23.2 occurring in the electrical engineering industry, and is lower than that found in the chemical industry (36.4) and mechanical engineering $(41 \cdot 1){ }^{2}$ The incidence of 46.8 found in certain occupations, however, suggests that these occupations are more hazardous than the two equivalent industries.

The most important causes of injury are the handling of objects $(32.6 \%)$ and falls $(32.3 \%)$, which together account for $65 \%$ of accidents observed. The importance of materials handling as a cause of accident is probably understated, since detailed examination of accidents involving falls shows that 
often a fall is associated with handling awkward objects. These two causes of accident are more prominent than in other industries-for example, the percentages of accidents caused in mines by handling and falls are $15.5 \%$ and $21.6 \%$ respectively, and in factories $27.4 \%$ are caused by handling and $14 \cdot 6 \%$ by falls. $^{3}$

The annual mean rate of accidents observed in the light occupations of the TI of 10.4 is less than that previously examined in light occupations in the construction industry, whose accident rate has been reported as 29.8 (Nicholson, personal communication, 1978). Nevertheless, comparison of the occupations most at risk in the TI (the top 23 codes) with heavy occupations in the construction industry shows accident rates in the TI (46.8) closely approaching those of the construction industry $(54 \cdot 2)$.

The finding that accidents occur most frequently in the middle age groups, 31-45 year olds having an accident rate of 29.3 and the 16-30 year olds a rate of $17 \cdot 6$, conflicts with recent data from the construction industry, which shows that the incidence of accidents in the younger age group is nearly twice that of the middle age group (Nicholson, personal communication, 1978). In the construction industry the high incidence of accidents in the younger population is partly attributable to inexperience, supported by evidence that $50 \%$ of accidents in the construction industry occur during the first year of employment (Shepherd, unpublished observations); similarly, $60 \%$ of accidents in the TI in the USA ${ }^{4}$ are suffered by employees who have had less than 12 months' experience. In this study, however, $93 \%$ of the accidents occur after the first year of employment. This, considered with the observation of the highest frequency of accidents occurring in the middle age groups, suggests that some of the injuries that are assumed to be the direct result of the accident, particularly posterior trunk injuries, may result from several years of chronic cumulative damage. Another factor affecting the incidence of accidents in the younger workers is the training policy; in the TI we are informed that all young recruits follow an apprenticeship of several years during which time they are carefully supervised, and recruitment to those outside jobs which constitute the bulk of the top 23 codes is of more mature men-that is, not school leavers.

The decline in accident frequency observed in the groups aged over $\mathbf{4 5}$ may result from several factors. Firstly, most of the works supervisors are aged between 40 and retirement age, and although assigned to the one occupation, they do not undertake active physical work to the same degree as previously, and hence are not exposed to the same hazards. Secondly, by this age they are very experienced in their work and are less likely to get into an unknown situation which gives rise to accidents. Thirdly, this group could be considered as "the survivors," since particularly with reference to posterior trunk injuries, we are told that those who have had a serious accident leading to a permanent disability, however slight, may either have left the industry or been redeployed in lighter duties; thus those remaining are less susceptible to injury or accident.

The observation of 23 occupations having accident rates higher than the overall average immediately suggests those occupations to which preventive measures should first be applied. The finding that this group have accident rates four to five times greater than other trades in the industry suggests that one or more factors related to these occupations give rise to higher accident rates. Analysis of the age distribution of a sample population of these occupations showed a distribution significantly different from the overall engineers' population ( $p<0.001$ ), being weighted more heavily in the middle age groups and fewer younger workers (reflecting the recruiting policy for this group), but even allowing for this distribution, the observed number of accidents is twice the expected number.

The distribution of posterior trunk injuries by age in the top 23 codes differs from the overall distribution; the younger age groups having a relatively higher rate of back injuries. This earlier onset of back morbidity seen in those occupations entailing heavier physical work was also observed by Magora and Taustein ${ }^{5}$ in a study of eight basic occupationsheavy industrial workers, light industrial workers, farmers, nurses, policemen, bus drivers, Post Office clerks, and bank clerks. They noted, when considering the two groups with highest and lowest incidence of low back pain, that low back pain appeared at an earlier age in heavy industrial workers and nurses, the incidence in the populations in the 18-30 age group being $34.5 \%$ and $32 \%$ respectively compared with $8.4 \%$ for Post Office clerks, and $0 \%$ for policemen. The difference when the incidence in heavy industrial workers and nurses was compared with that in Post Office clerks and policemen was significant $(p<0.001)$. Their view that the age of onset of low back pain and associated injuries is significantly earlier in heavy occupations is also supported by $\mathrm{Hult}^{6}$ and Anderson et al. ${ }^{7}$

Related to the earlier finding that $65 \%$ of posterior trunk injuries were caused by handling accidents is the observation that the top 23 occupations have a slight elevation in the relative number of handling accidents, and a significantly higher proportion of accidents from handling poles, ladders, and manhole and jointbox covers. Previous studies have highlighted the problem of handling heavy objects as the 
cause of back injuries. Roantree ${ }^{8}$ noted that in nearly $50 \%$ of 111 cases of back lesions with a clear history as to cause, lifting weights was implicated. In 100 cases of back pain in the engineering industry 39 were caused by lifting and 33 by twisting movements of the spine, 25 of which occurred when lifting. ${ }^{9}$ Hence one of the factors affecting accident incidence in the top 23 codes is the number of specific handling problems encountered which expose the individual to a risk of posterior trunk injury.

The seasonal variation of accident incidence observed can be attributed to several factors. Initially it was observed that there was a seasonal fluctuation in the incidence of certain accident causes-most pronounced in the incidence of falls. Since falls account for $32.3 \%$ of all three-day-plus accidents, any large variation found in the incidence of falls alone would have a significant effect on the incidence of all accidents. Also, since nearly $70 \%$ of three-day-plus accidents are suffered by workers who spend most of their time outside, inclement weather conditions are likely to affect the incidence of all accidents, accounting for the increase seen from October to February.

\section{Conclusions}

Industrial accidents, particularly posterior trunk injuries, occur frequently in the middle age groups of telecommunications engineers. This finding supports the suggestion that back injuries arise commonly as the result of an accumulation of minor damage over several years. The earlier onset seen in occupations with higher accident rates suggest that stresses imposed on the trunk are greater, and induce posterior trunk injuries at an earlier age.

Industrial accidents also appear more frequently in those occupations having relatively more specific handling problems. Handling accidents and falls appear to be the two major causes of accidents. Posterior trunk injuries constitute one quarter of all accidents, materials handling giving rise to twothirds of these injuries.

We thank the Post Office telecommunications branch, for whom this work was carried out under contract, and the many willing volunteers who participated in the study.

\section{References}

${ }^{1}$ Nie N, Hadlai C, Jenkins J, Steinbrenner K, Bent D. Statistical package for the social services. 2nd ed. New York: McGraw Hill, 1975.

${ }^{2}$ Health and Safety: Industry and Services, 1975. London: HMSO, 1977.

${ }^{3}$ Senneck CR. Over-3-day absences and safety. Appl Ergonomics 1975;6:147-53.

4 Wilkins GF, Schilling JW, Schowalter E. Industrial back injuries-bell system. Arch Ind Health 1957;15:91-100.

${ }^{5}$ Magora A, Taustein I. An investigation of the problem of sick leave in the patient suffering from low back pain. Ind Med 1969;38:80-90.

${ }^{6}$ Hult L. Cervical, dorsal and lumbar spinal syndromes. Acta Orthop Scand 1954;suppl 17.

${ }^{7}$ Anderson JAD, Duthie JJR, Moody BP. Social and economic effects of rheumatic diseases in a mining population. Ann Rheum Dis $1962 ; 21: 342-51$.

${ }^{8}$ Roantree WD. The mobilisation and use of heavy mining equipment as a cause of backstrain. Medical Office Broadsheet 1963;4:3.

${ }^{9}$ Glover JR. Back pain and hyperaesthesia. Lancet 1960;1: $1165-9$. 